express invitation; on this occasion they explored widely through Southern and Northern Rhodesia, Nyasaland and Tanganyika. The results of these journeys were described by Hutchinson in his attractive book, "A Botanist in Southern Africa" (Gawthorn, 1946).

In 1936 Hutchinson was appointed keeper of museums at Kew. He received the honorary degree of LL.D. from the University of St Andrews in 1934, and in 1947 was made a fellow of the Royal Society in recognition of his services to science in the field of plant elassification. His "Families of Flowering Plants" (2 vols.) has become a standard work In the horticultural field his special interest for many years was the genus Rhododendron and later the genus Sorbus. He has received various horticultural honours, including the Victoria Medal of Honour of the Royal Horticultural Society. In his retirement Dr. Hutchinson hopes to complete a revision of Bentham and Hooker's "Genera Plantarum" and also some botanical works of a more popular kind. The good wishes of all his friends go with him.

\section{American Awards for Work on Penicillin}

The United States Medal for Merit, the highest award made by the President of the United States to a civilian, has been presented to Sir Alexander Fleming and also to Sir Howard Florey for their work on penicillin. The citations accompanying the awards are as follow :

Sir Alexander Fleming, for exceptionally meritorious conduct in the performance of outstanding services to the United Nations during 1939-45. Sir Alexander has distinguished himself and benefited mankind through his fundamental researches and exceptional scientific contributions on the therapeutic use of penicillin, which were of major importance to the successful completion of the mission of the medical services in World War II. His personal and enthusiastic assistance to medical officers in the European Theatre of Operations greatly advanced the earlier application of the penicillin programme than would otherwise have been possible in that theatre, thereby contributing materially to the care of the sick and wounded soldiers and to the conservation of man-power. Penicillin was a significant factor in halving the death-rate from wounds of United States troops in World War II as compared with those of World War I. Thousands of soldiers are alive to-day, and other thousands have been spared crippling disabilities, because of Sir Alexander's monumental contributions on penicillin.

Sir Howard Florey, for exceptionally meritorious conduct in the performance of outstanding services to the United Nations during 1939-45. Sir Howard distinguished himself during this period through important contributions and fundamental researches in the development of penicillin. His foresight in conferring with United States scientists of the National Research Council in June 1941 greatly furthered the knowledge of this antibiotic agent and its potentialities, and made possible the large-scale production of penicillin, for the incalculable benefit of the sick and wounded. His vigorous leadership in the researches and utilization of this agent stimulated medical scientists to greater effort and greatly extended the field of usefulness of penicillin. His enthusiastic personal assistance to medical officers in the European Theatre of Operations was of utmost importance in providing penicillin therapy for sick and wounded troops in that theatre at an earlier date than would otherwise have been possible. The significant role of penicillin as a major factor in reducing deaths from wounds is apparent, for the rate was halved over the death-rate of World War I. Thousands of soldiers are now alive and other thousands have been spared crippling injuries because of Sir Howard's leadership in the development and utilization of this antibiotic agent.

\section{Guthrie Lecture of the Physical Society}

THE Guthrie Lecture of the Physical Society will be given this year by Sir George Thomson, his subject being "The Growth of Crystals". The Lecture will be given on June 4 at the Science Museum, London, S.W.7, at 5 p.m. During the First World War, Prof. Thomson made notable contributions to aerodynamics; later his attention was directed to the demonstration of the wave nature of the electron and the proof of de Broglie's Law. These experiments, now classical, earned him the Nobel Prize in 1937. After his appointment to the chair of physics at the Imperial College of Science and Technology, the work on electron diffraction in particular was continued and led naturally to an interest in surface layers and to the general question of crystal structure. During the Second World War, Sir George Thomson held a number of important Government posts and more recently was the British delegate to the Atomic Energy Commission of the United Nations Organisation.

\section{Inter-Departmental Committee on Overseas Scientific Relations}

THE Lord President of the Council, on the advice of the Advisory Council on Scientific Policy, has approved the setting-up of an Inter-departmental Committee on Overseas Scientific Relations to consider and advise on questions of United Kingdom Government policy on matters of overseas scientific relations. Sir Edward Appleton is chairman, and in addition to representatives of Government departments, the membership will include the foreign secretary of the Royal Society, representatives of the British Council and of the Conference of Research Associations, and two university men of science. The secretary of the Committee is Mr. H. L. Verry, head of the Overseas Liaison Division, Department of Scientific and Industrial Research, 142 Piccadilly, london, W.1.

\section{Scientific and Industrial Research in Palestine}

THE Government of Palestine Board for Scientific and Industrial Research, which is the successor of the Scientific Advisory Committee of the Palestine War Supply Board formed in 1942, has issued a "Report of Activities, April 1945-March 1948" accompanied by summaries of research and a list of publications of the Board (Jerusalem : P.O. Box 607 and the Hebrew University. Pp. 56. 150 mils. ; 3s.). A list of standing advisory committees and subcommittees and their personnel is included, as well as of the projects carried out during 1946-48 and the institutions in which the research was located. Most of the investigations are being published in scientific periodicals, but full reports of all of them are available on request at the Office of the Board. The Sub-Committee for Citrus Products has compiled a card index of scientific literature on citrus products to serve as a reference work for further research. The index covers the period 1927-46 and will be 
published in book form. The Sub-Committee for Water Research has dealt mainly with physicochemical aspects of the problems, and a literature survey on the influence of ions on plants and soils has been published. Dr. M. Reiner, while studying methods of testing asphalt and bitumen used at the Road Research Laboratory in Britain, commenced investigations which led to the discovery of an important phenomenon in the deformation of asphalt, and visited England again in 1947 to follow up this discovery. A summary of his report on the rheological properties of bitumen and asphalt is included among the research summaries, as well as a joint note with A. Arnstein and M. Teinowitz on the loading test of reinforced concrete structures. Other research reports deal with bovine leptospirosis, the chemical composition of fodder plants in Palestine, chemical composition and nutritive value of foodstuffs produced in Palestine, citrus products, thermostable thromboplastin from human placenta, metabolic disturbance in diabetes, work hardening of polycrystalline metals, and several chemical investigations.

\section{Royal Photographic Society's Annual Exhibition}

TнE Royal Photographic Society's ninety-third annual exhibition is to be held at the Society's House at 16 Princes Gate, London, S.W.7, during September and October this year. It will be in two parts, the first devoted to pictorial and colour photography and the second to scientific, technical, Nature and record photography. Lantern slides, colour transparencies and stereoscopic exhibits will be on view throughout the whole exhibition. The Scientific and Technical Group of the Society is very anxious to make the second part of the exhibition fully representative of the best work in all branche.3 of modern applied photography. It may not be sufficiently widely known that the exhibition is open to all users of photography, and can assist them by giving them a standard against which to judge their own work. The Scientific Section of the exhibition is divided, for convenience, into seven classes : photomicrographs; radiographs (medical and industrial being judged separately); astronomical and meteorological ; geological and metallurgical ; survey (aerial and terrestrial); medical and surgical ; other scientific photographs. Nature photography, record and technical photography (architectural, press, commercial and advertising) and kinematography are in separate sections. Scientific and technical films should be entered in the last section. Photographs produced in the course of scientific research are particularly welcomed.

Two awards are made annually by the Society in the Scientific Section, namely, the Hood Medal for meritorious performance in any branch of practical photography, and the Rodman Medal for outstanding work, preferably in photomicrography or radiography. The closing date for receiving entries is July 24 .

\section{American Section of the International Union of Crystallography}

THE U.S. National Research Council has appointed a group of leading chemists, physicists and mineralogists to act as provisional executive committee of the American Section of the International Union of Crystallography, which will hold its first general assembly and congress at Harvard University during July 28-August 3. The Committee consists of Prof.
L. O. Brockway, University of Michigan ; Prof. M. J. Buerger, Massachusetts Institute of Technology; Prof. J. D. H. Donnay, Johns Hopkins University; Prof. I. Fankuchen, Polytechnic Institute of Brook. Iyn; Prof. C. Frondel, Harvard University; Dr. D. Harker, General Electric Co. ; Dr. M. L. Huggins, Eastman Kodak Co. ; Prof. A. L. Patterson (chairman), Bryn Mawr College; Prof. L. Pauling, California Institute of Technology; Prof. F. Seitz, Carnegie Institute of Technology; Prof. A. N. Winchell, American Cyanamid Co.; and Dr. R. W. G. Wyckoff, National Institute of Health. The Committee will recommend to the National Research Council a permanent constitution for the American Section of the Union, and will also advise the Council with regard to any matters which are of general concern to crystallographers in the United States. The British National Committee for Crystallography was announced in Nature of March 13, p. 390.

\section{Education in Industry and Commerce}

THE Minister of Education has recently announced that Lieutenant-General Sir Ronald Weeks has accepted the chairmanship of the newly established National Advisory Council for Education in Industry and Commerce. The Council has been set up to consider the national aspects of the policies of the ten regional councils and academic boards which have been constituted to develop and co-ordinate schemes for higher technological education in their respective regions. Sir Ronald was deputy chief of the Imperial General Staff from 1942 until 1945 and is now deputy chairman of Vickers, Ltd., and chairman of the English Steel Corporation, Ltd.

\section{Conference on the Education of the Young Worker}

A Conference on "The Education of the Young Worker" will be held at Manchester College, Oxford, during July 12-17, under the auspices of the Oxford University Department of Education, whose director is Mr. M. L. Jacks. The Conference aims at bringing together representatives of all the voluntary and statutory organisations, of central and local government departments, and others concerned in the education, employment and welfare of young people between the ages of fifteen and twenty, who are no longer receiving full-time education. It is hoped to produce a statement of policy applicable to the needs of these young people, setting out as clearly as possible the goals to be achieved in further education, whether in county college, industry or during leisure time. Suggestions will be made for practicable methods by which these goals can be achieved through the right co-ordination and administration of all available resources to form an integrated service, and some form of agreement will also be sought on the recruitment and training of all personnel who will be responsible for these young people. Wellknown people, especially experienced in some aspect of this work, have been invited to speak at the Conference. The Conference itself will be divided into eight Commissions, namely : (1) county colleges ; (2) leisure-time activities ; (3) education in and through the job; (4) education for and in the Services ; (5) recruitment and training of personnel ; (6) differentiation in provision between the sexes; (7) differentiation between town and country; (8) administration and co-ordination. Further inform. ation can be obtained from the Director, University Department of Education, 15 Norham Gardens, Oxford. 